Original Research Article

\title{
Evaluation of pharmacovigilance concepts among healthcare professionals in Davangere, Karnataka, India
}

\author{
Shashank Shastry ${ }^{1}$, Santosh Kumar M. ${ }^{2 *}$
}

${ }^{1}$ Student, ${ }^{2}$ Department of Pharmacology, JJM Medical College, Davangere, Karnataka, India

Received: 27 April 2019

Accepted: 31 May 2019

*Correspondence to:

Dr. Santosh Kumar. M,

Email: Sankumar20123@

gmail.com

Copyright: (C) the author(s), publisher and licensee Medip Academy. This is an openaccess article distributed under the terms of the Creative Commons Attribution NonCommercial License, which permits unrestricted noncommercial use, distribution, and reproduction in any medium, provided the original work is properly cited.

\begin{abstract}
Background: Adverse drug reactions are one of the leading causes of morbidity and mortality worldwide. Timely detection and reporting of adverse drug events through pharmacovigilance is the best tool we have to prevent adverse drug reaction. One of the major reasons for underutilization of pharmacovigilance in India is deficit in awareness, attitude and practice of pharmacovigilance. The objective of this study was to assess these parameters among healthcare professionals in our hospital.

Methods: 200 health care professionals (post graduate students, undergraduate students, interns and nurses) took part in the study. A pre-designed questionnaire structured to obtain information on pharmacovigilance was used for evaluation. Questionnaire also enquired on factors that deter respondents from reporting.

Results: Among undergraduates, the satisfactory responses for knowledge, awareness and practice of pharmacovigilance were $12 \%, 72 \%$ and $42 \%$ respectively and for postgraduates it was $52 \%, 48 \%$ and $26 \%$ respectively. For interns it was $4 \%, 38 \%$ and $8 \%$ respectively and nurses $8 \%, 18 \%$ and $26 \%$ respectively. Only $1 \%$ of undergraduates and $14 \%$ of postgraduates showed satisfactory responses to all three categories evaluated. Undergraduate students had a significantly higher awareness scores among the categories $(p<0.05)$. When it comes to knowledge and practice there was not much differences between groups. Lack of time to report was the most cited factor across all categories discouraging reporting.

Conclusions: Results are encouraging among undergraduate students, but not significantly better than postgraduates. The poor performance among interns and nurses is due to lack of awareness. A strong basic foundation course regarding pharmacovigilance in academics will help in effective implementation of pharmacovigilance.
\end{abstract}

Keywords: Awareness, Knowledge, Practice, Pharmacovigilance

\section{INTRODUCTION}

As per WHO, Pharmacovigilance is "The science and the activities which relate to the detection, assessment, understanding and the prevention of adverse effects or any other drug-related problems". ${ }^{1}$ Adverse drug reactions are the most important health care problem throughout the world, affecting people with varying magnitudes and one of the reason for both morbidity and mortality., ${ }^{2,3}$ Recent epidemiological studies have estimated that adverse drug reactions are the fourth to sixth leading causes of death and that they represent $5 \%$ to $10 \%$ of the hospital costs. ${ }^{4}$

Pharmacovigilance starts from the clinical stage and continues throughout the product life cycle of the drug, mainly divided as pharmacovigilance during premarketing (that is clinical trial phase) and post-marketing. Pharmacovigilance is particularly concerned with the 
adverse drug reactions which are defined as an unintended and noxious responses to a drug that occur at doses normally used for the prophylaxis, diagnosis, or therapy of disease, or for the modification of physiological function. ${ }^{5}$

Spontaneous and timely reporting of adverse drug reactions plays a major role in detection of unsuspected, sometimes serious, unusual adverse drug reactions not detected previously in clinical trials. In fact, early detections of serious adverse drug reactions can even lead to ban and withdrawal of the drug from market, hence safety of patients is ensured. The WHO collaborating center for international drug monitoring is located in Sweden under the name Uppsala Monitoring Centre (UMC). Pharmacovigilance Programme of India (PvPI) was setup to initiate adverse drug reaction monitoring centers (AMCs) throughout the country to implement Pharmacovigilance in India.

In a country like India, pharmacovigilance by health care professionals becomes an important lifeline for safety of patients. This is primarily due to the large and diverse population, medications available without prescriptions, people on alternate medicines and low socioeconomic status. Though India is the third largest consumers of the drug in the world, we only contribute $1 \%$ in terms of adverse drug reaction reporting against the world rate of $5 \% .{ }^{6}$ Some of the major reasons for under reporting are deficit in awareness, attitude and practice of pharmacovigilance among health care professionals. As post-graduate students and interns are the first lines of contact in a teaching hospital, it is imperative to evaluate the awareness, knowledge and practice of pharmacovigilance among these health care professionals along with practising doctors. Also, nurses and pharmacists are involved in the system, thus even they should know about adverse drug reaction reporting.

Since time immemorial, the use of medicines has been associated with adverse effects. "There are 3 actions of a drug: the one you want, the one you don't want, and the one you don't know about" (DJP Barker). ${ }^{7}$
In addition to the obvious morbidity, and the mortality which are caused by them, adverse drug reactions are also an economic burden on our healthcare system as they prolong the hospital stay and increase the cost of the treatment. One proven and effective method to safeguard the patients from adverse drug reactions is to implement pharmacovigilance.

Hence awareness, knowledge and practice of pharmacovigilance in clinical setup have become essential among health care professionals. The current study was undertaken to evaluate these parameters among healthcare professionals in tertiary care teaching hospital.

\section{METHODS}

The study was done after obtaining approval of Institutional Ethics committee of JJM Medical College Davangere, Karnataka, India. The study subjects were post graduate students, undergraduate students, interns and nurses. The study was conducted over a period of three months. A total of 200 study subjects ( 50 in each category) took part in the study. The study instrument was a predesigned questionnaire structured to obtain information on awareness, knowledge and practice of pharmacovigilance. These questions were designed based on earlier studies published for assessing the knowledge, awareness and practice of pharmacovigilance. The study subjects were personally briefed about the study and questionnaire. The participants were given 20 minutes to answer the questionnaire and they were not allowed to consult anyone during this time. Participant's anonymity with regards to name was maintained, but their designations were noted. The questions were designed in such a way that each question had only one correct answer. The questionnaire has 20 questions which assessed the Knowledge (6), Awareness/attitude (5) and Practice of pharmacovigilance (8). One question determined aspects which deter subjects from reporting adverse drug reaction. Incomplete responses were rejected. The questionnaires were, then analyzed by grading the respondents into three categories: Poor, unsatisfactory, and satisfactory as shown in Table 1.

Table 1: Grading of respondents (score range).

\begin{tabular}{|lllll|}
\hline Level(Questions) & Poor & Unsatisfactory & Satisfactory & Max possible score \\
\hline Awareness (5) & $1-2$ & $3-4$ & $5-6$ & 6 \\
\hline Knowledge (6) & $1-2$ & 3 & $4-5$ & 5 \\
\hline Practice of PV (8) & $1-2$ & $3-4$ & $5-8$ & 8 \\
\hline
\end{tabular}

\section{RESULTS}

A total of 200 respondents answered the questionnaire, resulting in a response rate of $100 \%$. Among undergraduates, the satisfactory response for knowledge, awareness and practice of pharmacovigilance was $12 \%$, $72 \%$ and $42 \%$ respectively. Only one subject had satisfactory response to all three categories. Among postgraduates, the satisfactory response for knowledge, awareness and practice of pharmacovigilance was $52 \%$, 
$48 \%$ and $26 \%$ respectively. $14 \%$ of respondents had satisfactory scores in all 3 categories of questions. Among interns, the satisfactory response for knowledge, awareness and practice of pharmacovigilance was just $4 \%$, $38 \%$ and $8 \%$ respectively. Among nurses, the satisfactory response for knowledge, awareness and practice of pharmacovigilance was just $8 \%, 18 \%$ and $26 \%$ respectively. No respondents in both interns and nurses had satisfactory scores in all 3 categories of questions. The mean scores for postgraduates, undergraduates, interns and nurses for awareness, knowledge and practice are shown in Table 2.

Table 2: Mean scores of awareness, knowledge, and practice of PV among healthcare professionals.

\begin{tabular}{|lllllllll|}
\hline & \multicolumn{2}{c}{ Undergraduates } & \multicolumn{2}{c}{ Postgraduates } & \multicolumn{2}{c|}{ Interns } & \multicolumn{2}{c|}{ Nurses } \\
\hline PV(Questions) & Mean & SD & Mean & SD & Mean & SD & Mean & SD \\
\hline Awareness (6) & 4.98 & 1.048 & 4.48 & 1.135 & 4.04 & 1.248 & 3.44 & 1.168 \\
\hline Knowledge (5) & 2.64 & 1.091 & 2.88 & 1.727 & 1.88 & 1.243 & 2.2 & 1.296 \\
\hline Practice (8) & 4.00 & 1.400 & 3.6 & 1.697 & 2.92 & 1.197 & 4.04 & 1.399 \\
\hline
\end{tabular}

Undergraduate students had a significantly higher awareness scores than interns, postgraduates and nurses $(\mathrm{p}<0.05)$. Postgraduates and interns had a significantly higher awareness scores than nurses $(\mathrm{p}<0.05)$. When it comes to knowledge and practice of pharmacovigilance there was no much differences between the groups with an exception of undergraduates compared to interns (Table $3)$.

Table 3: Statistical comparison between groups using Students t test.

\begin{tabular}{|lllllll|}
\hline & \multicolumn{2}{c}{ A wareness } & \multicolumn{2}{c}{ Knowledge } & \multicolumn{2}{c|}{ Practice } \\
\hline & t value & p value & t value & p value & t value & p value \\
\hline UG vs PG & 2.2643 & 0.0312 & -0.822 & 0.379 & 1.2727 & 0.1881 \\
\hline UG vs Interns & 4.0359 & 0.0002 & 3.2163 & 0.0023 & 4.1038 & 0.0003 \\
\hline UG vs Nurses & 6.8647 & 0.0000 & 1.8179 & 0.0917 & -0.141 & 0.8767 \\
\hline PG vs Interns & 1.8251 & 0.1377 & 3.2884 & 0.0059 & 2.2918 & 0.0605 \\
\hline PG vs Nurses & 4.4670 & 0.0003 & 2.2037 & 0.0314 & -1.400 & 0.1629 \\
\hline Interns vs Nurses & 2.4558 & 0.0154 & -1.2472 & 0.2571 & -4.257 & 0.0003 \\
\hline
\end{tabular}

Table 4: Factors discouraging reporting of adverse drug reactions.

\begin{tabular}{|lllll|}
\hline Factors & Undergraduates (\%) & Postgraduates(\%) & Interns(\%) & Nurses(\%) \\
\hline Not interested to report & 0 & 4 & 6 & 5 \\
\hline Lack of time & 28 & 47 & 29 & 39 \\
\hline $\begin{array}{l}\text { Single unreported case will not affect } \\
\text { database }\end{array}$ & 17 & 13 & 23 & 24 \\
\hline $\begin{array}{l}\text { Difficulty to decide whether adverse drug } \\
\text { reaction has occurred or not }\end{array}$ & 35 & 21 & 29 & 26 \\
\hline Not my professional duty & 20 & 0 & 3 & 5 \\
\hline Lack of information & 0 & 15 & 10 & 0 \\
\hline
\end{tabular}

Among various factors discouraging reporting of adverse drug reactions, lack of time to report adverse drug reactions was the most cited factor across all four categories of respondents with a maximum of $47 \%$ among postgraduates. Next most cited reason was that the respondents found it difficult to decide whether an adverse drug reaction has occurred or not, with a maximum of $35 \%$ among undergraduates.

The least cause of not reporting adverse drug reaction was not interested to report (Table 4). Higher percentage of undergraduates felt adverse drug reaction reporting is not 
their professional duty as compared to the other categories of respondents (Table 4).

\section{DISCUSSION}

Mean scores for all groups of respondents fell under the grading unsatisfactory for knowledge, awareness and practice of pharmacovigilance. This shows the poor attitude towards pharmacovigilance in the region of the study. It also highlights the lack of training and orientation of all categories of respondents in concepts of pharmacovigilance. Undergraduates were found to have significantly higher awareness scores than interns, postgraduates and nurses. This could be due to the recent inclusion of pharmacovigilance in the undergraduate curriculum, which interns may have missed during their education. When it comes to knowledge and practice of pharmacovigilance there was no much differences between the groups.

Survey on the knowledge, attitude and the practice of pharmacovigilance among the health care professionals in a teaching hospital in northern India by Hardeep JK et al noted similar observations as our study. ${ }^{8}$ In a similar study conducted in South India by Gupta KS et al, demonstrated that knowledge and attitude towards pharmacovigilance is gradually improving among healthcare professionals, but unfortunately the actual practice of ADR reporting is still deficient among them. ${ }^{9}$

Lack of time to report adverse drug reactions was the most cited factor discouraging adverse drug reaction reporting across all categories of respondents. Next most cited reason was that the respondents found it difficult to decide whether an adverse drug reaction has occurred or not. This could be due to the high workload in a tertiary care centre wherein all categories of respondents are preoccupied with other responsibilities and hence are unable to report adverse drug reactions even if they want to. Also, there might be inadequate education about the varied presentations of adverse drug reactions to all groups of respondents resulting in many adverse drug reactions going undetected and hence unreported. Many respondents across all categories also felt that a single reported adverse drug reaction would not affect the database, which reflects poor attitude towards pharmacovigilance. Higher percentage of undergraduates felt adverse drug reaction reporting is not their responsibility as compared to the other categories of respondents. This may be due to the limited exposure of undergraduates towards clinical practice.

In a similar study by Kumari $\mathrm{S}$ et al, the most discouraging factor for reporting an ADR was the health care professionals did not have sufficient time for it. The second factor was found that they fail to decide whether the ADR has occurred or not. Some health care workers believe that not reporting a single case may not make a big difference. ${ }^{10}$ A study by Santhosh et al found lack of time to report $\mathrm{ADR}(50.52 \%)$, belief that a single unreported case may not affect ADR database (11.15\%), and difficulty to decide whether ADR has occurred or not $(32.69 \%) .{ }^{11}$ Another similar study by Hardeep JK et al, found the perception of the reporting process being tedious, the lack of time, a poor knowledge on the reporting mechanism and inadequate expertise seemed to be the main reasons for not reporting the ADRs. ${ }^{8}$

Training in detection and reporting of adverse drug reaction is advisable for undergraduate, postgraduate and nursing curriculums. Active pharmacovigilance should be advocated to all healthcare professionals. The varied presentations of adverse drug reactions should be taught and explained so that they aren't dismissed as ordinary events. A yearly interactive session on pharmacovigilance can be used to orient health care professionals in the hospital and update the concepts taught. This will improve the reporting and care of patients with adverse drug reaction. Their doubts regarding the adverse drug reaction database and procedure of reporting should be comprehensively tackled. Adverse drug reaction reporting should be made accessible by providing reporting forms in all departments in the hospital. The forms should be promptly filled, and efforts must be taken to ensure the forms reach the authorities who would in turn report the adverse drug reaction. This would save time for all healthcare professionals and may improve adverse drug reaction reporting.

\section{CONCLUSION}

In conclusion this study shows there is a lack of understanding of importance of pharmacovigilance among healthcare workers, that to in a tertiary care centre. There is a urgent need in addressing this issue by various means like curriculum inclusion, yearly workshops and CME to propagate and implement pharmacovigilance among all health care workers.

\section{ACKNOWLEDGEMENTS}

Authors would like to thank all the students, interns and nurses from JJM Medical College who took part in the study. Authors are grateful to Anirudha N Sharma and Pratyaksh PV, House surgeons from JJM Medical College for their immense support for the study.

Funding: No funding sources

Conflict of interest: None declared

Ethical approval: The study was approved by the Institutional Ethics Committee

\section{REFERENCES}

1. The World Health Organization. Safety of medicines: A guide to detecting and reporting adverse drug reactions. Geneva, 2002. Available at: http://www.aaas.who.int/medicinedocs/en/d/jh2992e. Accessed 4 March 2019. 
2. Pirmohamed M, James S, Meakin S, Green C, Scott AK, Wally TJ, et al. Adverse drug reactions as cause of admission to hospital: prospective analysis of 18820 patients. Br Med J. 2004;329:15-9.

3. Lazarou J, Pomeranz BH, Corey PN. Incidence of adverse drug reactions in hospitalized patients: a metaanalysis of prospective studies. JAMA. 1998;279:1200-05.

4. Srinivasan R, Ramya G. Adverse drug reaction causality assessment. Int $\mathrm{J}$ Res in Phar Che. 2011;1(3):606-11.

5. Mishra H, Kumar V. Pharmacovigilance: current scenario in a tertiary care teaching medical college in North India. J Pharmaco. 2013;1(2):1-4.

6. Prakash S. Pharmacovigilance in India. Indian J Pharmacol. 2007;39(3)123.

7. SK Gupta. Post marketing Surveillance. In: Text book of Pharmacovigilance. 1st ed. New Delhi, Jaypee Brothers Medical Publishers(P) Ltd; 2011:75.

8. Hardeep JK, Rakesh K. A survey on the knowledge, attitude and the practice of pharmacovigilance among the health care professionals in a teaching hospital in northern India. J Clin Diagno Res. 2013;7(1):97-9.

9. Gupta SK, Nayak RP, Shivaranjani R, Vidyarthi SK. A questionnaire study on the knowledge, attitude, and the practice of pharmacovigilance among the healthcare professionals in a teaching hospital in South India. Pers in Clin Res. 2015;6(1):45-52.

10. Sunitha k, Anurag S, Pslaniappan S. Evaluation of knowledge, awareness, and attitude practice among nurses in pharmacovigilance at teritary care hospital in Delhi. J Harmo Res Pharm. 2015;4(1):76-86.

11. Madhusudhan SK, Shashikala GH. Evaluation of knowledge, awareness, and practice of pharmacovigilance among practicing doctors. Asian J Pharm Clin Res. 2016;9(3):283-6.

Cite this article as: Shastry S, Kumar SM.

Evaluation of pharmacovigilance concepts among healthcare professionals in Davangere, Karnataka, India. Int J Basic Clin Pharmacol 2019;8:1605-9. 